\title{
DISCLAIMER
}

This report was prepared as an account of work sponsored by an agency of the United States Government. Neither the United States Government nor any agency thereof, nor any of their employees, makes any warranty, express or implied, or assumes any legal liability or responsibility for the accuracy, completeness, or usefulness of any information, apparatus, product, or process disclosed, or represents that its use would not infringe privately owned rights. Reforence herein to any specific commercial product, process, or service by trade name, trademark, manufacturer, or otherwise does not necessarily constitute or imply its endorsement, recommendation, or favoring by the United States Government or any agency thereof. The views and opinions of authors expressed herein do not necessarily state or reflect those of the United States Government or any agency thereof.

\section{Interim Progress Report Addendum - Environmental Geophysics: Building E5032 Decommissioning, Aberdeen Proving Ground, January 1994 Resurvey}

M.D. Thompson, L.D. McGinnis, M.A. Benson, H.M. Borden, and C.A. Padar

Center for Environmental Restoration Systems, Energy Systems Division, Argonne National Laboratory, 9700 South Cass Avenue, Argonne, Illinois 60439

\section{Published as}

Environmental Geophysics at Aberdeen Proving Ground, Maryland:
Building E5032

for sponsor's use only

December 1994

Work sponsored by United States Department of Defense, United States Army, Aberdeen Proving Ground, Maryland 

with the exception of color reproductions. 


\section{DISCLAIMER}

Portions of this document may be illegible in electronic image products. Images are produced from the best available original document. 


\section{Preface}

This report is one of a series on environmental geophysical studies around perimeters of buildings in the Canal Creek Area of the Edgewood Area of Aberdeen Proving Ground. The series was initiated in 1991 at Building E5032, where techniques were evaluated and a design for the surveys was established. Studies at Building E5032 continued in January 1994, when additional surveying was conducted in an area approximately $50 \%$ larger than the original survey. New instrumentation, consisting of a continuously recording magnetometer and two electromagnetic induction tools, was used at this site. The new instrumentation improved diagnostic capabilities and provided more efficient data collection. The final product of this resurvey shows greater detail in locating several buried pipes or utilities. 


\section{Contents}

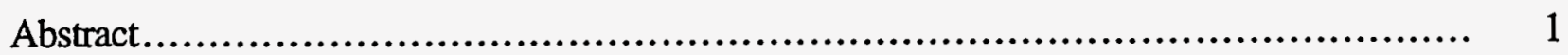

1 Introduction.................................................................... 1

1.1 Description of the Building E5032 Site....................................... 2

1.21994 Geophysical Survey ................................................... 4

2 Instrumentation.......................................................................... 5

2.1 Magnetometers ................................................................ 5

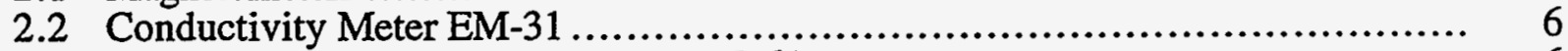

2.3 Time-Domain Millivolt Meter EM-61 ................................................... 6

3 Geophysical Measurements and Surveys....................................... 7

3.1 Magnetometer Measurements ................................................. 7

3.2 Conductivity Meter EM-31 Measurements............................................... 11

3.3 Time-Domain Millivolt Meter EM-61 Measurements ........................... 13

4 Discussion ........................................................................ 17

5 Conclusions ...................................................................... 19



Figures

1 General Location Map for Building E5032 …................................. 2

2 Site Map Showing the Outline of Building E5032 and the Survey Area..................................................................... 3

3 Map of the Total Magnetic Field Anomalies at Building E5032................. 8

4 Magnetic Anomalies North of Building E5032: 1994 Survey................... 10

5 Magnetic Anomalies North of Building E5032: 1991 Survey................... 10

6 Map of the Terrain Conductivity Anomalies at Building E5032 .................. 12

$7 \quad$ Map of the EMF Anomalies at Building E5032 .................................. 14

8 Trends of Observed Magnetic, EMF, and Conductivity Anomalies. and Locations of Cultural Features near the Northeast Corner of Building E5032 


\title{
Interim Progress Report \\ Addendum - Environmental Geophysics: \\ Building E5032 Decommissioning, \\ Aberdeen Proving Ground, \\ January 1994 Resurvey
}

by

\author{
M.D. Thompson, L.D. McGinnis, M.A. Benson, \\ H.M. Borden, and C.A. Padar
}

\begin{abstract}
Geophysical surveying around Building E5032 using three new continuously recording geophysical instruments - two types of electromagnetic induction instruments and a cesium vapor magnetometer that were unavailable at the time of the original survey - has provided additional information for defining the location of buried debris, vaults, tanks, and the drainage/sump system near the building. The dominant geophysical signature around Building E5032 consists of a complex pattern of linear magnetic, electrical-conductivity, and electromagnetic field anomalies that appear to be associated with drainage/sewer systems, ditches, past railway activity, the location for Building T5033 (old number 99A), and the probable location of Building 91. Integrated analysis of data acquired using the three techniques, plus a review of the existing ground-penetrating-radar data, allow a more thorough definition of the sources for the observed anomalies.
\end{abstract}

\section{Introduction}

Geophysical surveying around Building E5032 has been conducted as part of an effort by Argonne National Laboratory (ANL) to aid the decommissioning program for 29 buildings located in the Canal Creek Area of Aberdeen Proving Ground (APG). McGinnis and Miller (1991) reported the results of the original geophysical survey around Building E5032 and identified a potential contaminant source associated with a buried tank or iron vault north of the building. They also observed many isolated and/or clustered magnetic anomalies that were most likely caused by buried pipes or utility lines.

In January 1994, a resurvey was conducted around Building E5032 by using continuously recording equipment that had been unavailable at the time of the original survey. The purpose of this resurvey was twofold: (1) to further enhance knowledge of potential contaminant sources by surveying a larger area that encompassed such observed features as ditches and concrete footings and (2) to judge the efficacy of this newer set of geophysical tools in terms of ability to correctly detect/image the location of buried objects. 


\subsection{Description of the Building E5032 Site}

Building E5032 is located on the northwest corner of the intersection of Hoadley and Magnolia roads (Figure 1) and is situated in the north-central part of the Edgewood Area of Aberdeen Proving Ground, Maryland. The building is surrounded by drainage ditches, sumps, and concrete pads that are associated with activities performed at the building (see Figure 2) (EAI Corporation 1989). Also, the remnants of three railroad grades are present to the northwest and northeast of the building. Inspection of aerial photographs indicates that the railroad lines once extended south of the building.

The remains of two additional buildings are reportedly located in the survey area. Historical records indicate that a storage shack, Building T5033 (old number 99A), was located approximately $50 \mathrm{ft}$ north of Building E5032. If still present, this structure would occupy the northwestern corner of the parking apron adjacent to Building E5032. Another structure, Building 91 (old numbering system), was reported by the RCRA Facility Assessment to be near Building T5033 (Nemeth 1989). However, neither the date when Building 91 was demolished

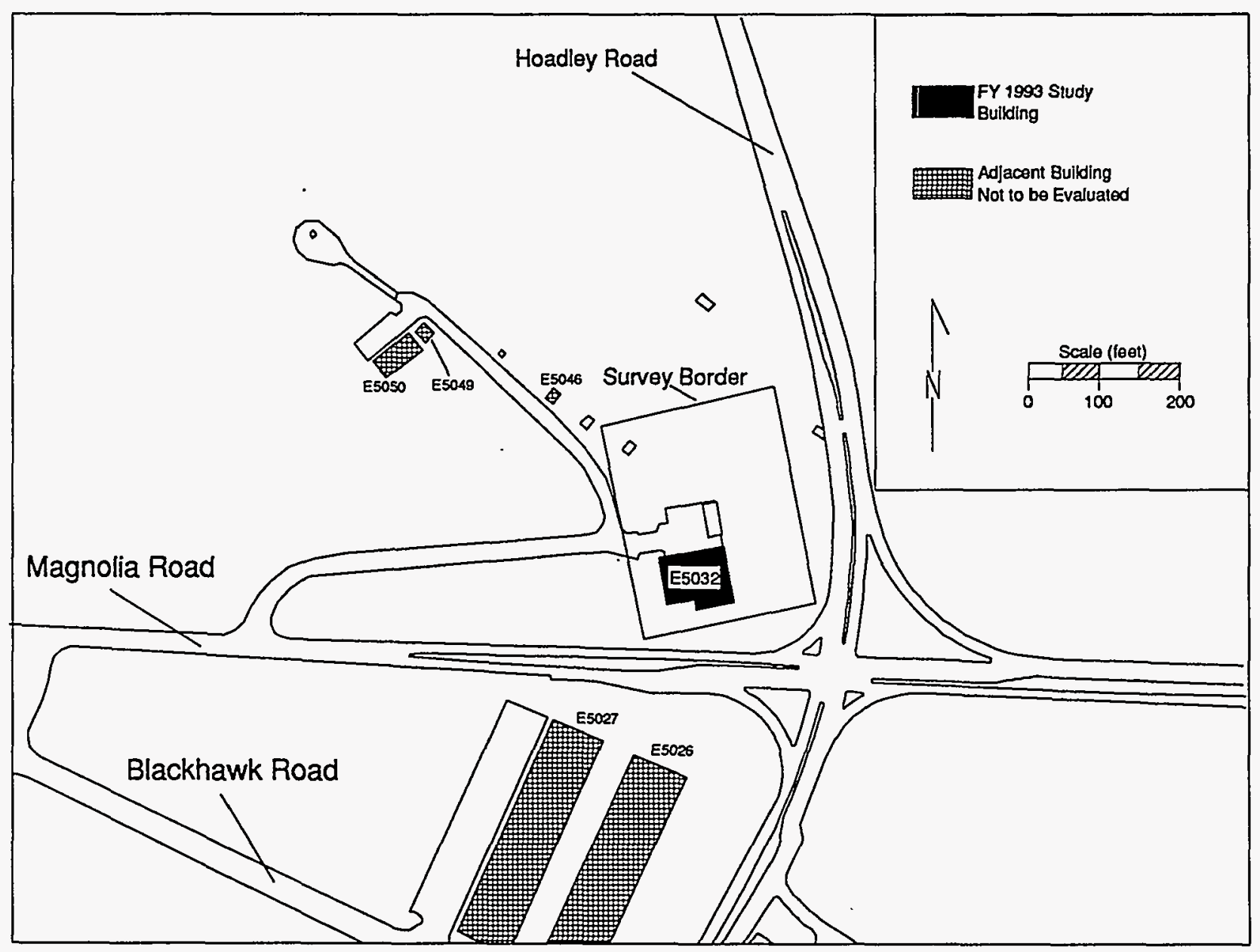

FIGURE 1 General Location Map for Building E5032 




FIGURE 2 Site Map Showing the Outline of Building E5032 and the Survey Area 
nor its exact location is known. Analysis of aerial photographs from 1957 shows a structure north of Building E5032, and this is interpreted to be Building T5033. None of the aerial photographs available to ANL show the Building 91 structure.

\subsection{Geophysical Survey}

Geophysical data were acquired during one day of field operation in January 1994 (as compared with three to four days required during the 1991 survey). On-site personal computers (both notebook and desktop), interactive software, and field equipment designed specifically for APG building studies were used to expedite data acquisition and processing. Surveys included total field magnetics, ground conductivity, and induced electromagnetic field (EMF) measurements. This data set complements that acquired in 1991, which consisted of total field magnetics measurements, vertical resistivity sounding, and ground-penetrating-radar (GPR) profiling. The integration of all five techniques allows a reliable interpretation of the shallow subsurface surrounding Building E5032.

The 1994 survey area was larger than that surveyed in 1991 and included an additional $20 \mathrm{ft}$ to the west, $75 \mathrm{ft}$ to the east, and $10 \mathrm{ft}$ to the north (see Figure 2). Three north-southoriented ditches in the northern half of the study area and a flat, grassy area in the eastern third of the study area are included in this study. The survey grid was oriented such that its primary axes were parallel to the building's walls, which are aligned roughly north-south and east-west. The new grid comprised an area measuring $240 \mathrm{ft}$ north-south by $210 \mathrm{ft}$ east-west.

Prior to geophysical surveying, wooden stakes were placed at site corners to mark the survey grid; the zero coordinate was considered to be the grid corner located southwest of the building. Positive coordinates were measured north and east, while negative coordinates were measured west and south of the zero coordinate. To correct data and/or locations indicated on the 1991 survey grid to the 1994 grid, the east-west coordinate of a 1991 data point must be subtracted from 115.

Geophysical measurements were recorded along north-south- and/or east-west-oriented profiles spaced at 5-ft intervals. Measurements along each profile were taken by continuously recording instruments. Depending on the instrument used and the walking speed of the instrument operator, the sample interval ranged from approximately one-third to two-thirds of a foot per measurement point. 


\section{Instrumentation}

\subsection{Magnetometers}

Magnetometer surveys are used for identifying such ferromagnetic objects as tanks, drums, drain pipes, water lines, and small ferrous objects. Building E5032 was surveyed twice, first in 1991 with the EDA OMNI-IV proton precession magnetometer, then in 1994 with the EG\&G Geometrics G-822L cesium vapor magnetometer. The OMNI-IV was operated in a point mode, and a magnetic measurement was recorded at 1 - $\mathrm{ft}$ intervals along each profile. The G-822L was operated in a continuously recording mode and acquired a magnetic measurement at intervals of approximately one-third of a foot.

Results from the 1994 survey and also from the geophysical survey at the "Ghost Town Complex" (McGinnis et al. 1994) show that the magnitudes of the magnetic data acquired using the OMNI-IV in its point mode have greater precision than those obtained with the G-822L. This resolution loss is interpreted to be due primarily to the mode of collection and not the quality of the instrumentation. If the G-822L were also operated in a point-acquisition mode, resulting magnetic anomaly maps would probably be very similar to those obtained using the OMNI-IV. However, the utility of the G-822L is lost when it is used in a point acquisition mode, because the rate of data acquisition is severely diminished. The data collected with the G-822L, especially when integrated with anomaly maps generated by the electromagnetic induction tools, still prove quite reliable in detecting buried, ferrous objects.

Because of the dipolar field, a magnetic anomaly caused by a source having a simple shape exhibits a characteristic signature consisting of a positive magnetic peak and at least one negative magnetic trough. If iron-rich waste is buried in the northern hemisphere of the Earth and becomes magnetized in the Earth's magnetic field, a large positive anomaly will occur over a symmetrically shaped body with a weak negative offset to the north. The horizontal distance between the paired peak and trough is directly proportional to the depth of burial and the size and shape of the source, whereas, the amplitude of the anomaly is inversely proportional to the square of the depth of burial. Metallic debris at or just below the ground surface produces strong, closely spaced magrietic peaks and troughs separated by high gradient areas.

When using the G-822L magnetometer, the sign of magnetic anomalies must be viewed with extreme caution, because in a region of high gradients, the magnetometer becomes "untuned" and provides zero readings. Data processing software designed for the G-822L bridges the zero gap with mean values taken from the last readable data along the profile. Thus, because of the bipolarity of magnetic anomalies and the variability of gradients, it is possible for an isolated anomaly or a lineament to change from a positive to a negative feature along the trend. For the purposes of this study, the polarity of the anomaly is unimportant, whereas the absolute strength and shape are important to the final interpretation. 


\subsection{Conductivity Meter EM-31}

Electrical conductivities were measured with the Geonics EM-31, an electromagnetic (EM) induction meter that measures mean terrain conductivity to depths of approximately $20 \mathrm{ft}$. In EM profiling, electrical current flow is induced in the ground by a transmitter (induction coil), and a receiver measures the secondary magnetic field caused by the low-intensity "eddy" currents induced in the subsurface. The magnetic field strength of these eddy currents is nearly linearly proportional to the terrain conductivity.

Data were collected at 0.5 -s intervals using the EM-31 and were stored on the OMNI 720 data logger, which can log quad-phase electrical conductivity data and in-phase inductive data for metals simultaneously, as well as store survey geometry. Data for this survey were recorded in quad-phase only. Internal software permits downloading directly into an on-site computer. Conductivity contouring is incorporated into the field acquisition procedure so that daily map outputs are available for observation and interpretation. EM methods were used extensively in the Edgewood Area at Beach Point, J-Field, and the Pilot Plant by ANL staff.

\subsection{Time-Domain Millivolt Meter EM-61}

Field data were obtained in millivolts ( $\mathrm{mV}$ ) with an EM-61 meter, a portable, time-domain, electromagnetic induction instrument that transmits an electrical pulse into the ground and measures secondary magnetic fields caused by metallic objects beneath the instrument. As a consequence of its dual coil arrangement, the instrument can be operated in modes designed to reduce its sensitivity to interference from metallic sources at the surface (such as steel buildings). Data are recorded on three channels, including a response from an upper coil ( $\mathrm{CH} 1)$, a lower coil $(\mathrm{CH} 2)$, and a coil difference (CH3).

Data were collected at a rate of three readings per second and were stored on the OMNI 720 data logger. Internal software permits downloading directly into an on-site computer. Inspection of the data set acquired at Building E5032 indicates that the millivolt measurements obtained from the lower coil ( $\mathrm{CH} 2)$ are sufficient to identify buried metallic sources within the gridded area. 


\section{Geophysical Measurements and Surveys}

Color-contour maps of the total magnetic field, terrain conductivity, and time-domain EMF data, constructed using software developed at ANL (Thompson 1994), are presented in this report. The data set is comprised of 28,040 magnetic measurements, 5,819 EM-31 measurements, and 7,624 EM-61 measurements. Two additional contour maps are presented, so that the total magnetic field as measured by the two magnetometers can be compared.

On each color-contour plot, the following coloring convention is maintained: Building E5032 is depicted as a solid white polygon; cement structures or pads as solid gray rectangles; drainage ditches and old railroad beds as black- or gray-outlined areas; and the parking area as a diagonally striped area. For clarity, the drainage ditch that extends around the eastern and southern sides of the building and ends southwest of the building is shown as a solid gray polygon. In addition, the large cement slab located northeast of Building E5032 is presented as a black-outlined rectangle, so that magnetic and EM anomalies were not covered.

The U.S. Geological Survey minimum curvature gridding program, MINC (Cordell et al. 1992), was used to grid the data. Documentation supplied with the MINC program suggested that grid intervals from one-half to one-fifth of the profile spacing will yield adequate gridding results for data acquired along profiles. A grid interval of $1.25 \mathrm{ft}$ was used for each set of grid data and represented a grid interval of one-fourth of the profile spacing $(5 \mathrm{ft})$.

\subsection{Magnetometer Measurements}

The total magnetic field anomaly map for Building E5032 is shown in Figure 3. Also shown are the locations of the sample points, which, due to the density of data collection, appear as solid lines on the figure. Magnetic highs and lows caused primarily by the Building E5032 corrugated steel walls dominate the contour diagram. The strong magnetic fields near the building distort and/or obscure smaller, local anomalies. Although some undulations in magnetic contours near the building are present, magnetic residual anomalies that might be produced by subsurface objects cannot be distinguished from anomalies having building sources.

Scattered, isolated anomalies exist to the south and southwest of Building E5032, lying just outside the area of the magnetic field that is disturbed by the building. These anomalies most likely represent shallow-buried ferrous objects that are probably construction debris in the fill material around the building.

An east-west trend of anomalies of alternating polarity begins at the northeast corner of the building and heads due east. The EAI Corporation report (1989) indicates that a sanitary sewer line underlies the location of this anomaly. This feature is also indicated in the EM-61 millivolt data as a strong positive trend and in the EM-31 data as a weak negative trend. 


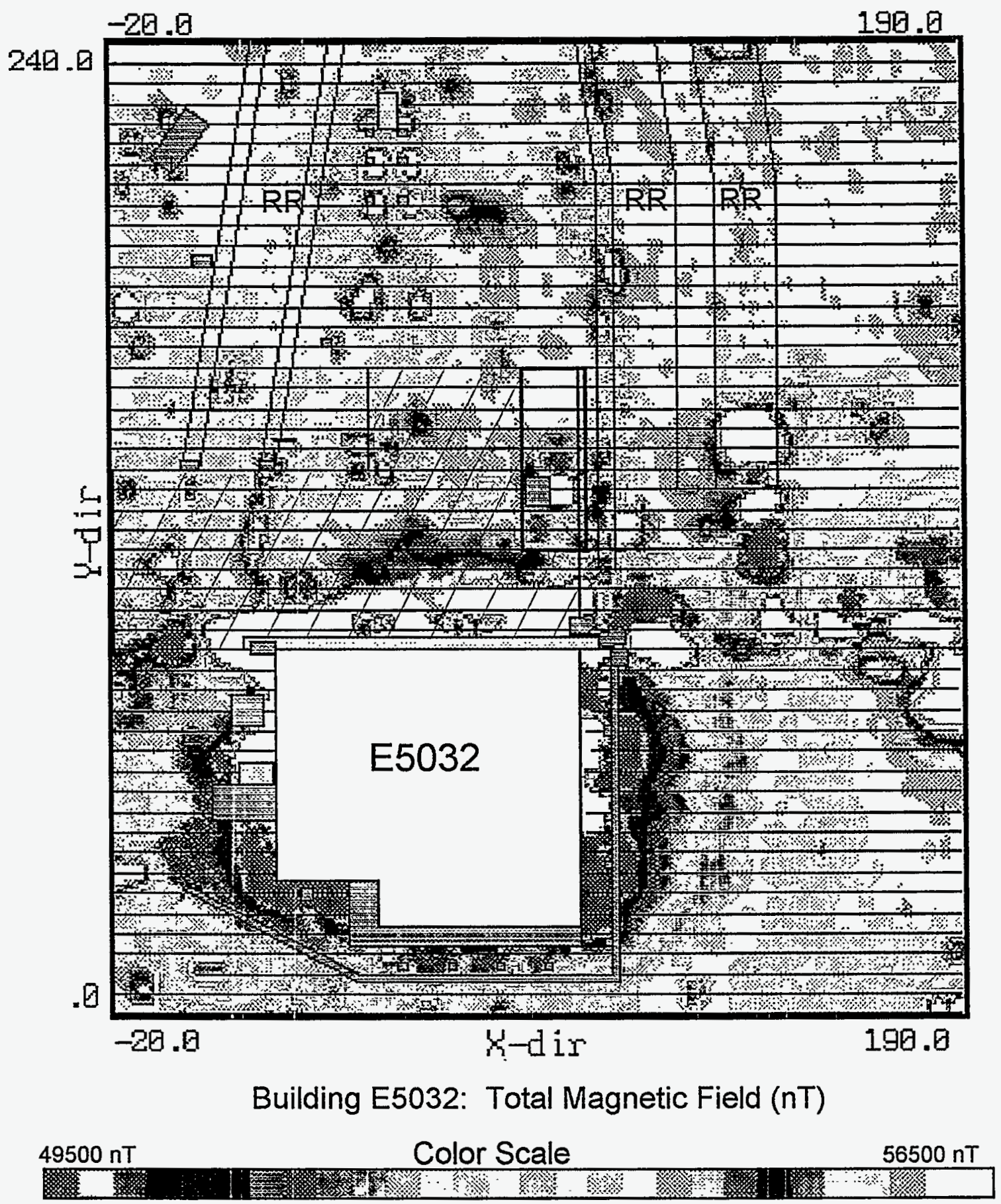

FIGURE 3 Map of the Total Magnetic Field Anomalies at Building E5032 (measured using a Geometrics G-822L cesium vapor magnetometer) 
A north-south trend of anomalies having alternating polarity extends north from the northeast corner of the building. This set of anomalies is aligned parallel with a ditch that lies adjacent to one of the old railroad grades near the building. These anomalies are interpreted to be caused by metal debris related to past railroad activity.

A more faint, but still distinct, set of northeast-trending magnetic anomalies is located approximately $45 \mathrm{ft}$ northeast from Building E5032. Some of these anomalies may be caused by railroad debris, as two railroad grades end in this area. However, intregated analysis with the terrain conductivity data supports the presence of a drain line, which begins as a culvert/drain structure near the northeast corner of the building and ends where an 8-in. steel culvert is exposed in a drainage ditch next to Hoadley Road (see Figure 2).

The magnetic anomaly with center at $90 \mathrm{E}, 130 \mathrm{~N}$ is due to a buried tank that underlies the concrete pad just east of the parking lot (see Figure 2). This anomaly appears as a paired positivenegative feature, with the associated negative offset to the north. The initial geophysical report concluded that this magnetic anomaly was caused by iron rebar in the cement pad, as no GPR "tank" signature was detected at depth (McGinnis and Miller 1991). However, Argonne personnel conducting a sampling program of underground storage tanks at APG indicate that a buried tank (filled with concrete) exists under the cement pad (Cobo 1994).

The northwest quarter of the survey grid is dominated by at least four different clusters of magnetic anomalies. In the extreme northwest part of the grid, an anomaly centered at $-15 \mathrm{E}, 215 \mathrm{~N}$ is associated with a concrete pad that has railcar tracks imbedded in it. The anomaly immediately to the south, with center at $-15 \mathrm{E}, 175 \mathrm{~N}$, does not have an associated surface feature.

The cluster of anomalies on the west side of the parking apron centered at $45 \mathrm{E}, 140 \mathrm{~N}$ are located approximately $8 \mathrm{ft}$ east of a pair of utility poles. The position of these anomalies roughly coincides with the location of former Building T5033 and may be associated with debris left from that building. Poor imaging by the GPR data (McGinnis and Miller 1991) does not allow a more definitive interpretation of this anomalous area.

A cluster of anomalies form a north-south trend from $200 \mathrm{~N}$ to $230 \mathrm{~N}$ along $50 \mathrm{E}$ and are anchored on their northernmost end by a buried tank or steel vault (McGinnis and Miller 1991). The gray rectangle at this location represents a barren spot on the ground surface. Six small concrete footings located to the south of the location of the buried tank have a direct correlation with a set of magnetic highs.

Magnetic anomalies with center at $45 \mathrm{E}, 180 \mathrm{~N}$ do not have a surface feature associated with them. It is suspected that these anomalies may reflect the old Building 91 structure. The GPR profiles in this region show that the subsurface has been disturbed, but they do not indicate a buried tank. 

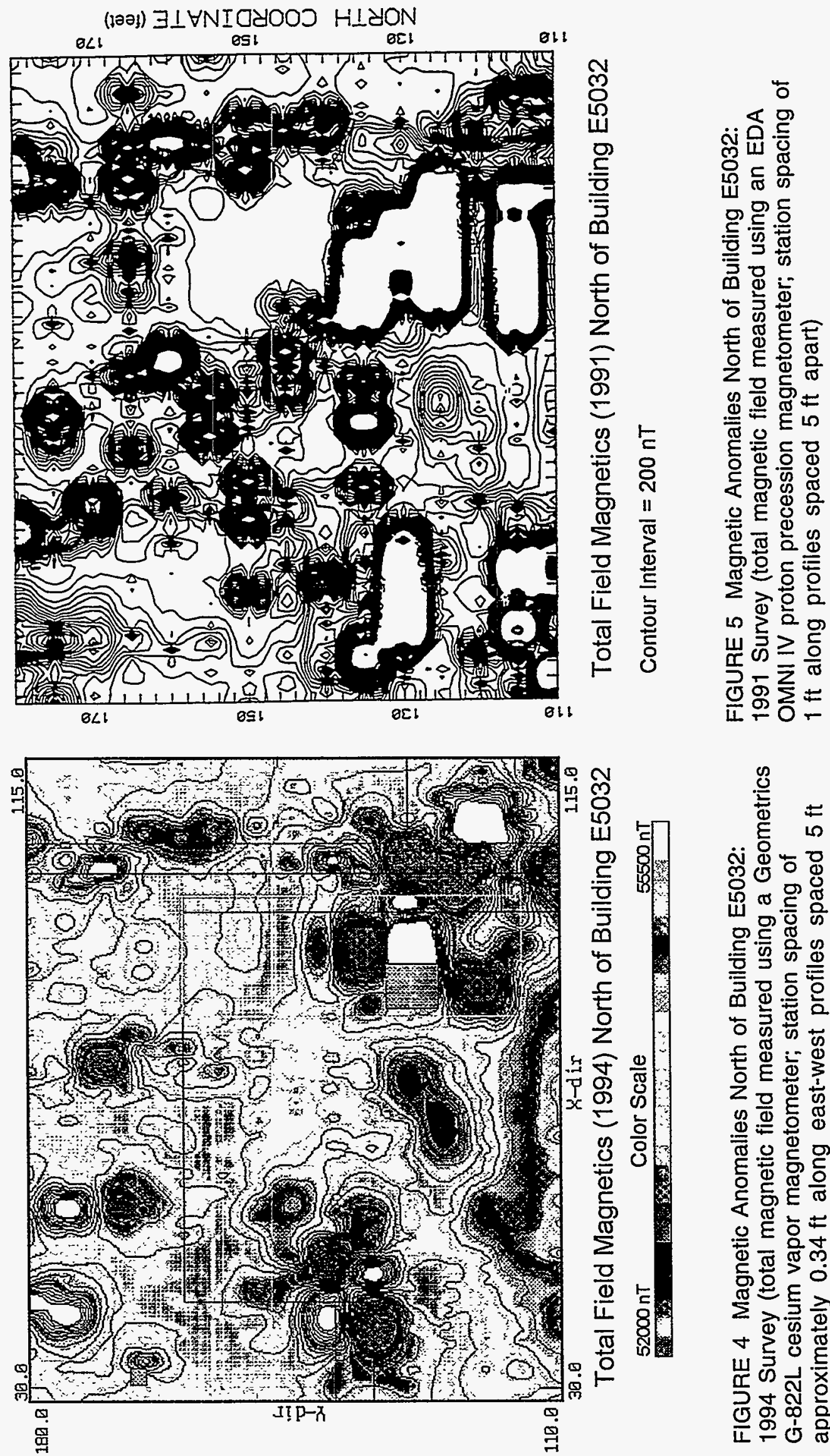

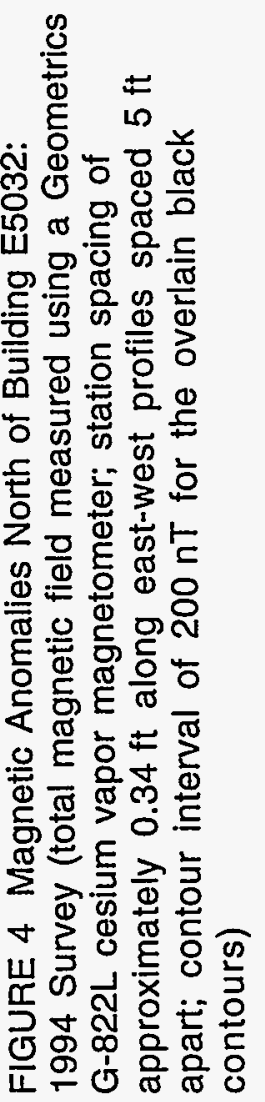


Figures 4 and 5 show the total magnetic field for an $85 \mathrm{ft} \times 75 \mathrm{ft}$ area located $20 \mathrm{ft}$ north of Building E5032. These figures have been included to illustrate the differences between the data collected by the two magnetometers (G-822L and OMNI-IV). Figure 4 was constructed from a subset of data from the 1994 survey, and Figure 5 is a reprint of Figure 8 from the report of McGinnis and Miller (1991). In Figure 4, contour lines were constructed using a contour interval of $200 \mathrm{nT}$ and a contour range from 52,000 to $55,500 \mathrm{nT}$, and overlain onto the color image. The magnetic contours shown in Figure 5 were constructed using a 200-nT contour interval.

Of importance are that the G-822L magnetometer (1994 survey) detects many, but not all, of the anomalies indicated by the 1991 data and that the G-822L data exhibit lower total magnetic field relief. The lower magnetic relief is due in part to the G-822L sensor head being held slightly higher in elevation than the OMNI-IV counterpart (which was placed directly on the ground) and in part to the nonstationary acquisition mode. In the continuously recording mode, the G-822L magnetometer does not have sufficient time to retune itself in areas of rapidly changing magnetic fields.

\subsection{Conductivity Meter EM-31 Measurements}

Horizontal profiling with the conductivity meter EM-31 provides a map of mean conductivity from the surface to a 20-ft depth around Building E5032 (Figure 6). The EM-31 data were acquired at a 0.5 -s sampling rate along the same transects traversed with the magnetometer. The color-contoured electrical-conductivity data shown in Figure 6 are dominated by linear trends and isolated anomalies. Some field distortion is observed in close proximity to the building. The spatial relationships between the conductivity anomalies and the observed anthropogenic features provide a strong basis by which to interpret the EM-31 data

The northwestern quarter of the grid area shown in Figure 6 is dominated by four isolated conductivity lows centered at $10 \mathrm{E}, 220 \mathrm{~N} ; 45 \mathrm{E}, 225 \mathrm{~N} ; 50 \mathrm{E}, 195 \mathrm{~N}$; and $50 \mathrm{E}, 135 \mathrm{~N}$. All four of these conductivity anomalies have equivalent magnetic and EMF counterparts (see Figures 3 and 7). The anomaly at $10 \mathrm{E}, 220 \mathrm{~N}$ is adjacent to, and west of, a concrete slab that has railcar tracks imbedded in it. The anomaly at $45 \mathrm{E}, 225 \mathrm{~N}$ is associated with a buried tank (or steel vault), previously identified from resistivity, magnetic, and GPR signatures by McGinnis and Miller (1991). Reexamination of the GPR profiles in the vicinity of the EM anomaly at 50E,195N indicates that the underlying soil has been disturbed, but the profiles do not indicate the presence of a buried tank. The foundation for Building T5033 may still be present and acting as the source for the anomalous low centered at 50E,135N. This anomaly has magnetic and EMF equivalents. No other surface feature is present in this locality. 


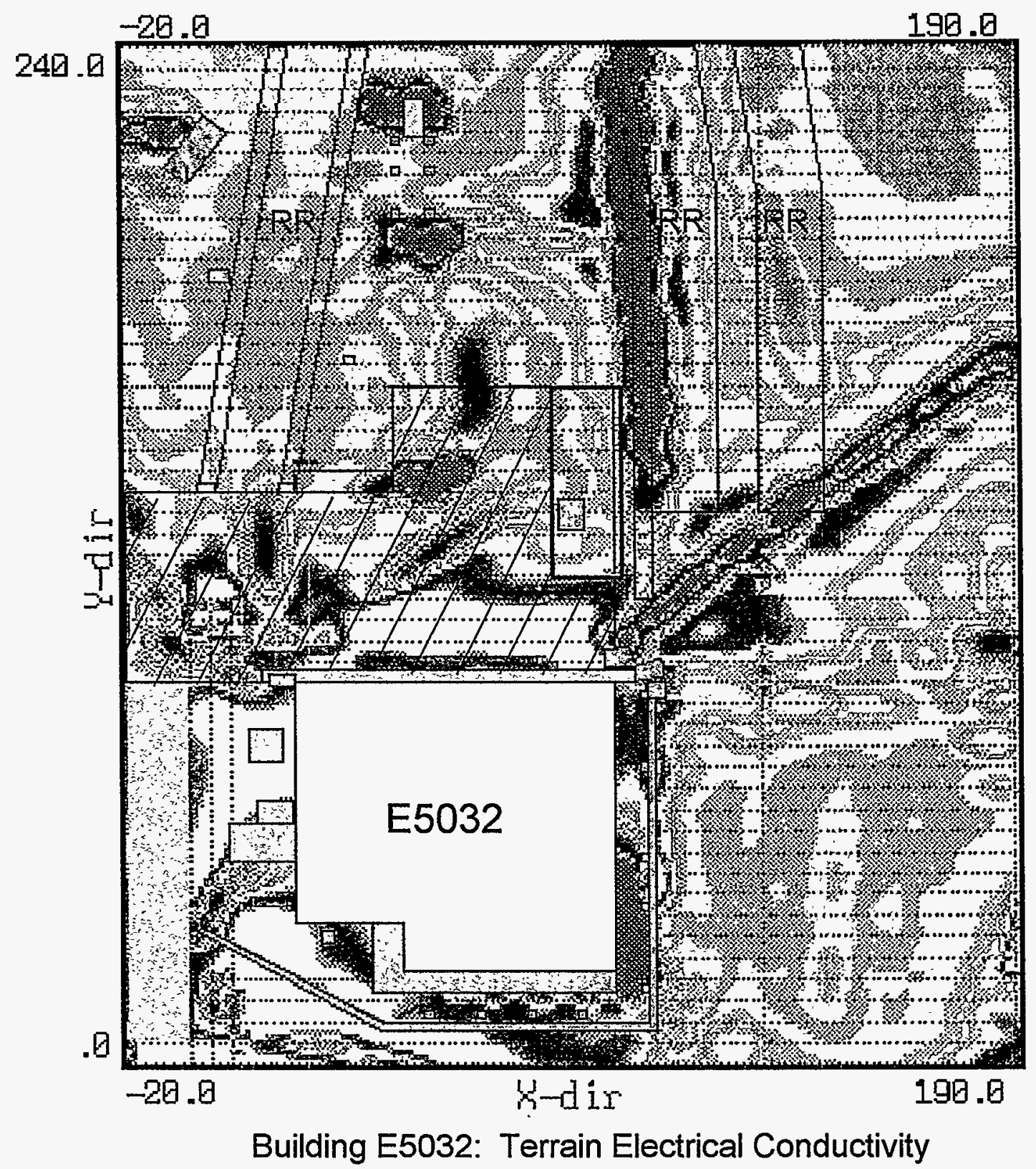

\begin{tabular}{|c|c|}
\hline$-20 \mathrm{mS} / \mathrm{m}$ & Color Scale \\
\hline s.t. & ঋख \\
\hline
\end{tabular}

FIGURE 6 Map of the Terrain Conductivity Anomalies at Building E5032 (measured using a Geonics EM-31 instrument) 
A northeast-southwest-oriented conductivity low extends from the northeast corner of the building to the eastern edge of the survey area, where it terminates in the vicinity of an exposed steel culvert (see Figure 2). This anomaly also has magnetic and EMF equivalents. The presence of the steel culvert, and the fact that drain lines/pipes are observed in the grate structures at the northeast corner of the building, requires that this conductivity anomaly be interpreted as due to a buried drain line. Similar conductive trends have been observed elsewhere at APG (McGinnis et al. 1994), and they have been interpreted as representing buried sewer, water, or utility lines.

A north-south-trending conductivity low is spatially located over a north-south-trending ditch that lies adjacent to an abandoned railroad grade. Magnetic and EMF anomalies are observed along this same trend. Although the ditch may have metallic debris buried within it that might be the source for these anomalies, the strength of this anomaly and its similarity to the northeasttrending conductivity low argue for the presence of a buried drain or sewer line.

A northeast-southwest-trending conductive low is observed in the parking-lot area immediately north of Building E5032, extending from $40 \mathrm{E}, 115 \mathrm{~N}$ to $80 \mathrm{E}, 135 \mathrm{~N}$, and appears to connect with a possible buried tank located under the concrete slab north of the building. Its southwest terminus becomes obscured in a high-conductivity area that is related to road grade and/or building effects.

Conductivity anomalies located northwest of the building, under the driveway/parking area, are probably caused by observed metal storm drains that run north-south beneath the driveway. A 20 -ft long, north-south-oriented conductivity low, with a southernmost extent at $15 \mathrm{E}, 125 \mathrm{~N}$, is offset approximately $5 \mathrm{ft}$ west from the exit point for the easternmost storm drain. Another conductivity low trends northwest from the building's corner and exits along the western edge of the survey grid at coordinate $120 \mathrm{~N}$. This pattern of EM anomalies is interpreted as being caused by interference effects from two or more storm drains.

In the southwest grid corner, a northeast-southwest-trending minimum extends from a sump works on the western side of the building (at $35 \mathrm{E}, 60 \mathrm{~N}$ ) and terminates where it intersects the drainage system that extends around the southern and eastern sides of the building (at $0 \mathrm{E}, 35 \mathrm{~N}$ ). The EM-31 data strongly indicate the presence of a drain line that connects to this drainage system, as there is no associated surface feature.

\subsection{Time-Domain Millivolt Meter EM-61 Measurements}

A color-contour map constructed from data taken with the time-domain millivolt meter EM-61 on the lower coil channel (CH2), which corresponds to the signal from the surface to a depth of approximately $9 \mathrm{ft}$, is shown in Figure 7. The solid gray rectangle along the western edge of the contour plot (from $25 \mathrm{~N}$ to $90 \mathrm{~N}$ ) demarks an area where no data were collected. Figure 7 is dominated by east-west- and north-south-oriented positive EMF trends, by isolated anomalies, and by clusters of anomalies. Characterization of major anomalies is discussed below. 




\begin{tabular}{|c|c|c|}
\hline & Color Scale & $275 \mathrm{mV}$ \\
\hline 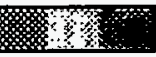 & W. & \\
\hline
\end{tabular}

FIGURE 7 Map of the EMF Anomalies at Building E5032 (measured using a Geonics EM-61 instrument) 
An east-west-oriented, positive EMF anomaly extends across the survey area along profile coordinate $95 \mathrm{~N}$ (just north of Building E5032). The eastern half of this anomaly has a magnetic equivalent and is weakly indicated by the electrical conductivity data. A sanitary-sewer line most likely causes this anomaly, as the EAI report (1989) placed a sewer line near the northeast corner of the building. Also, a very subtle, east-west elongated, surface depression is observed in the grassy area east of Building E5032 in the same spatial position occupied by the EMF anomaly.

A north-south-oriented positive anomaly starts near the northeast corner of the building and exits the survey area to the north. This trend is located in the same spatial position as north-south magnetic and conductivity anomalies and overlies a ditch that is immediately adjacent to an abandoned railroad grade. Buried metal debris is the most likely source for this anomaly.

The northeast-southwest-trending cluster of anomalies that project from the northeast corner of Building E5032 have magnetic counterparts, and the cluster overlies a conductivity anomaly observed in the EM-31 data. The EMF anomalies are interpreted to be related in part to the drain line observed by the EM-31 data and in part to debris left over from past railway activity.

Strong, positive EMF anomalies are associated with rebar and a buried tank under the cement pad located north of the building at coordinates $90 \mathrm{E}, 130 \mathrm{~N}$. A recent sampling program of underground storage tanks at APG conducted by Argonne staff found a cement-filled tank at this location (H. Cobo 1994).

Scattered, isolated, positive anomalies southwest of the building have equivalent anomalies in both the magnetic and conductivity maps. These anomalies are interpreted to be ferrous debris associated with construction/operation of the facility.

Immediately northwest of the building, two positive, north-south-trending EMF anomalies are spatially associated with culverts that underlie the driveway. The rugoseness of the anomalies is probably due to mislocated sample points. In this area, each sample position was interpolated from adjacent fiducial markers, but the positions were not correctly located because the profiles were traversed first east-to-west and then west-to-east. This reversing of data acquisition causes the instrument operator to slightly misjudge the true location of the sample point. In later surveys of small areas, this deficiency will be overcome by surveying in one direction only.

A matched pair of EMF anomalies, centered approximately $50 \mathrm{ft}$ north of the building at coordinates $60 \mathrm{E}, 135 \mathrm{~N}$ and $40 \mathrm{E}, 140 \mathrm{~N}$, is in the location once occupied by Building T5033. Magnetic and electrical conductivity anomalies also are observed in this spatial position. No other surface feature is observed that would produce these anomalies.

The set of north-south-trending, positive EMF anomalies, located from $45 \mathrm{E}, 225 \mathrm{~N}$ to $45 \mathrm{E}, 175 \mathrm{~N}$ is anchored on its north end by a buried vault or steel tank (McGinnis and Miller 1991). At the south end, these anomalies probably reflect the old Building 91 location. GPR profiles reported in 1991 by McGinnis and Miller show that the subsurface has been disturbed in this area. 
Two positive EMF anomalies in the northwest corner of the survey grid are coincident with a north-south-oriented ditch. These anomalies are interpreted to be caused by railroad-related debris on the basis of inspection of aerial photographs and the close proximity of railroad tracks.

The other isolated EMF anomalies in the northern half of the survey area do not have associated surface features, but they are most likely caused by ferrous debris associated with past railway activity. 


\section{Discussion}

The dominant geophysical signature at Building E5032 consists of linear trends of magnetic and electromagnetic anomalies that are coincident with observed drainage ditches, drain lines, and other anthropogenic features. None of the geophysical instruments completely defines each anomaly source, and therefore a comprehensive analysis requires multiple geophysical techniques.

Observed drain openings and grates (Figure 8) and their locations relative to geophysical anomalies suggest that at least two, and possibly three, drain line/sewer systems extend from the northeast corner of the building to the east, northeast, and north. The eastward-heading line has a strong, positive EMF anomaly (measured by EM-61); an alternating polarity magnetic anomaly; a weak conductivity low (measured by EM-31); and a subtle, surface depression associated with it. The northeast-trending drain line is represented by a strong, negative conductivity anomaly and appears as a discontinuous sequence of magnetic and EMF anomalies. The north-trending anomaly is depicted as a continuous EMF high, a linear trend of isolated magnetic anomalies, and a strong conductivity low. This last anomaly is directly associated with a drainage ditch that may have once been filled with railroad-related debris. Other possibilities for the cause of the northsouth anomaly are a buried drain line or amphibolite fill.

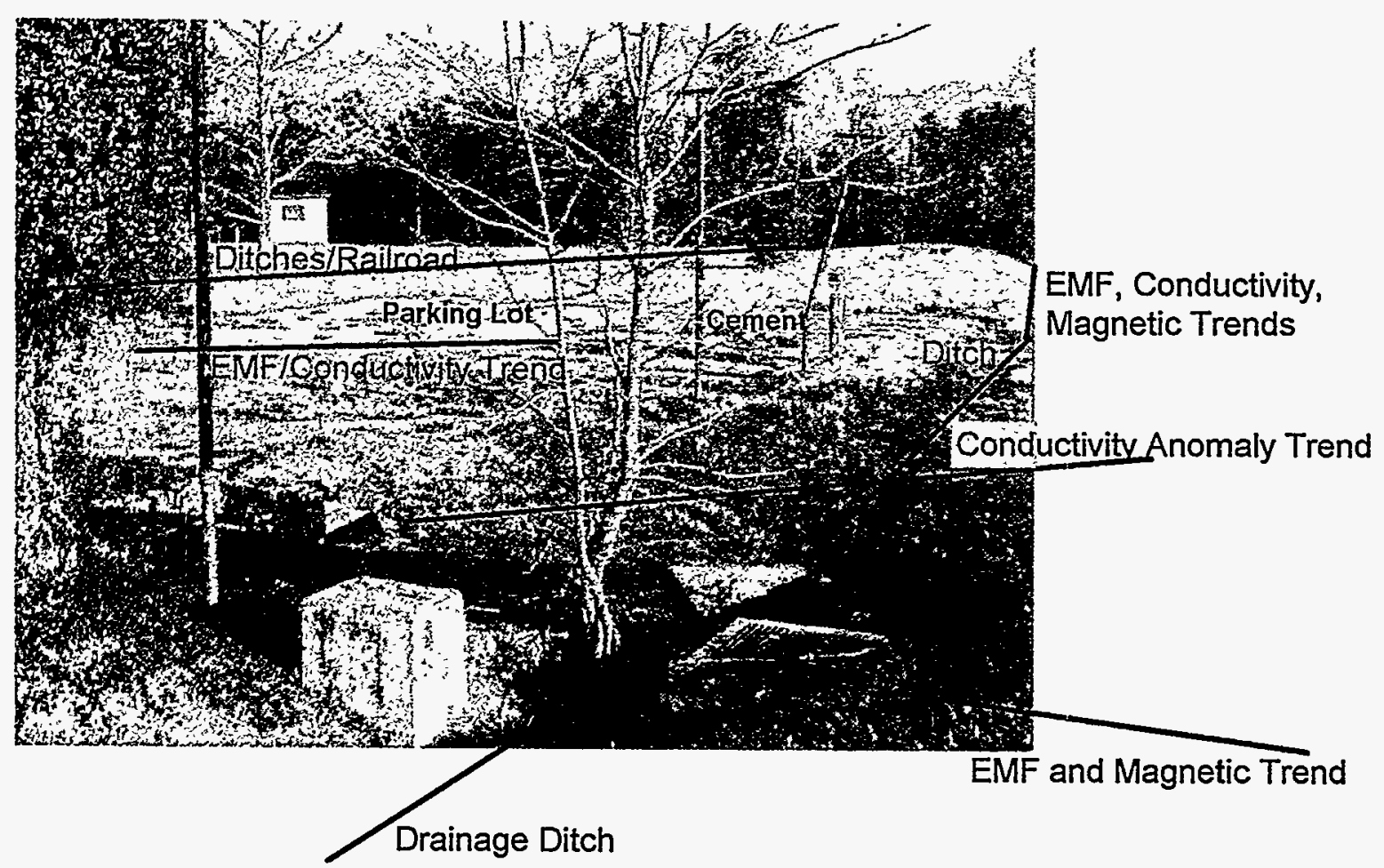

FIGURE 8 Trends of Observed Magnetic, EMF, and Conductivity Anomalies and Locations of Cultural Features near the Northeast Corner of Building E5032 (looking towards the northwest) 
Two other possible drain lines are indicated by the geophysical data. The first, which is located north of the building, appears to connect the building with the tank buried under the cement pad. This anomaly is oriented northeast-southwest and is represented by a conductivity low; a weak magnetic negative; and a faint, positive EMF anomaly. The strong geophysical anomaly produced by Building E5032 obscures the southwest extent of this feature. However, careful scrutiny of the EMF data suggests that this anomaly does reach the northwest corner of the building.

The second drain line was detected southwest and west of Building E5032 and appears to connect a sump unit on the west side of the building with the perimeter drainage system that extends around the southern and eastern sides of the building. This anomaly is marked by a conductivity low that bisects a region of higher conductivity. The spatial relationship among the anomaly's location, the sump, and the drainage system indicates the presence of a connecting drain line.

A cluster of isolated anomalies, consisting of conductivity lows, EMF highs, and alternating-polarity magnetic anomalies, is located from $45 \mathrm{E}, 225 \mathrm{~N}$ to $45 \mathrm{E}, 190 \mathrm{~N}$ and is produced by at least one buried vault or steel tank, whose presence was originally confirmed by GPR and horizontal-resistivity data (McGinnis and Miller 1991). The southern portion of these anomalies is probably caused by buried remnants of Building 91, which, according to the RCRA Assessment (Nemeth 1989), was located in this region. The GPR data obtained during the 1991 survey show that the subsurface is disturbed at this location. However, the GPR data do not show the signature of a buried tank.

A conductivity low, an EMF high, and a complex pattern of magnetic anomalies are located approximately $50 \mathrm{ft}$ north of Building E5032 and probably represent the Building T5033 structure, which was used as a storage facility. No surface features are associated with these anomalies, and the GPR profiles were limited by poor depth penetration in this area. Immediately east of these anomalies is a concrete pad that is underlain by a cement-filled tank. The presence of this tank is detected by both the magnetics and the EMF data.

Other isolated, unidentified magnetic, conductivity, and EMF anomalies litter the area around Building E5032. On the basis of inspection of aerial photographs, the cause of these anomalies is most likely ferrous debris discarded during past railway activities. 


\section{Conclusions}

The following conclusions regarding the geophysics of the area around Building E5032 can be drawn from the survey data for total field magnetics, ground conductivity, and EMF measurements:

1. A prominent northeast-southwest-trending conductivity lineament extends from the northeast corner of the building and exits the survey area at the eastern border, near where a steel culvert is exposed (see Figure 2). Magnetic anomalies of alternating polarity and a trend of EMF positives also mark parts of the conductivity anomaly. The presence of sewer grates next to the building and the steel culvert to the northeast indicate that a drain/storm line is the source of these anomalies.

2. An east-west trending, positive-amplitude, EMF anomaly extends across the survey area along profile number $95 \mathrm{~N}$ (just north of Building E5032) and is interpreted to be a sanitary sewer line. The eastern half of the EMF anomaly is represented as a trend of alternating-polarity magnetic anomalies and a very weak negative-conductivity anomaly. In addition, a subtle, east-west-oriented depression, spatially aligned with the geophysical anomalies, is observed in the grassy area east of Building E5032.

3. The magnetics and induced electromagnetic measurements all detect an anomalous, north-south-trending lineament that begins $20 \mathrm{ft}$ north of the northeast corner of the building and is spatially located over a north-southoriented ditch. Debris associated with past railway activity is interpreted to be the source for the magnetic and EMF anomalies. However, the strength of the conductivity anomaly (Figure 5) suggests the potential for an underlying drain line.

4. A north-south-trending cluster of anomalies, from $45 \mathrm{E}, 225 \mathrm{~N}$ to $45 \mathrm{E}, 190 \mathrm{~N}$, is anchored on the north end by a buried vault or steel tank and may be related to the old Building 91 structure indicated in the report of McGinnis and Miller (1991).

5. The conductivity data (measured by EM-31) indicate a northeast-southwesttrending conductivity low that extends from a sump works located on the building's western wall to the opening of the drainage ditch that runs around the southern and eastern perimeter of the building. The shape and strength of this anomaly indicate the presence of a buried drain line connecting the sump works and the drainage ditch. 


\section{References}

Cobo, H., 1994, personal communication, Argonne National Laboratory, Argonne, Ill.

Cordell, L., J.D. Philips, and R.H. Godsen, 1992, Potential Field Geophysical Software: Version 2, Open-File Report 92-18, U.S. Geological Survey.

EAI Corporation, 1989, Historical Records Search and Site Survey of Edgewood Area Buildings, Final Report, prepared by EAI Corporation, Abington, Md., for U.S. Army Chemical Research, Development, and Engineering Center, Aberdeen Proving Ground, Md., under contract No. DAA15-87-D0021.

McGinnis, L.D., and S.F. Miller, 1991, Interim Prógress Report - Geophysics: Building E5032 Decommissioning, Aberdeen Proving Ground, ANL/ESD/TM-20, Argonne National Laboratory, Argonne, $\mathrm{Ml}$.

McGinnis, L.D., M.D. Thompson, and S.F. Miller, 1994, Environmental Geophysics: Buildings E5485, E5487, and E5489 Decommissioning, The Ghost Town Complex, Aberdeen Proving Ground, Maryland, ANL/ESD/TM-78, Argonne National Laboratory, Argonne, 11.

Nemeth, G., 1989, RCRA Facility Assessment Report, Edgewood Area, Aberdeen Proving Ground, Maryland, prepared by U.S. Army Environmental Hygiene Agency.

Thompson, M.D., 1994, COLMX software, unpublished. 